\title{
7. ENTRE MACHADO DE ASSIS E O ABOLICIONISMO PENAL: EM BUSCA DE ALTERNATIVAS AO SISTEMA PENAL
}

\author{
Daniel Achutti ${ }^{1}$ \\ Marco Antônio de Abreu Scapini ${ }^{2}$
}

Resumo: o artigo aborda a equivocada política criminal de expansão do direito penal e, a seguir, aponta para a violência performática do Direito. Trabalha a relação entre a Casa Verde, de $O$ Alienista, de Machado de Assis, e o fenômeno do hiperencarceramento brasileiro, e sugere a necessidade de rompimento com a lógica que estrutura o sistema penal. Projeta, por fim, a justiça restaurativa como política criminal concreta para romper com o punitivismo contemporâneo, a partir das contundentes críticas do abolicionismo penal.

Palavras-chave: direito penal; política criminal; hiperencarceramento; abolicionismo penal.

Abstract: the article discusses the mistaken criminal policy of expansion of the criminal law, and then points to the performative violence of the Law. Works the relationship between the Casa Verde, from $O$ Alienista, written by Machado de Assis, and the Brazilian phenomenon of over incarceration, and suggests the necessity to break up with the logic which sustains the penal system. Designs, finally, restorative justice as a concrete criminal policy to provide a break to the contemporary punitivism, from the strong criticism of penal abolitionism.

Key words: criminal law; criminal policy; over incarceration; penal abolitionism.

A razão não pode atestar a existência da loucura sem comprometer-se ela mesma nas relações da loucura. $O$ desatino não está fora da razão, mas nela, justamente, investido, possuído por ela, e coisificado. Para a razão, é aquilo que há de mais interior e também de mais transparente, de mais oferecido. Enquanto a sabedoria e a verdade são sempre indefinidamente recuadas pela razão, a loucura nunca é nada do que a razão pode ter dela mesma.

Michel Foucault.

\footnotetext{
${ }^{1}$ Doutor em Ciências Criminais pela PUCRS, com período sanduíche na Universidade de Leuven - Bélgica (bolsa CAPES - processo n. 3770/10-9). Pesquisador e Professor de Direito Penal e Processual Penal no UNILASALLE e no CESUCA. Membro do Instituto de Criminologia e Alteridade (ICA), do ITEC e do IBCCRIM. Advogado.

${ }^{2}$ Mestre e Especialista em Ciências Criminais pela PUCRS. Professor de Direito Penal na Faculdade João Paulo II (Passo Fundo). Advogado.
} 


\title{
1. Introdução
}

As reflexões sobre o sistema penal e os desdobramentos da violência própria deste sistema não se esgotam. Aliás, num período em que o controle governamental manipula as massas com interesses específicos para a manutenção desta máquina de morte, a reflexão crítica e de resistência se mostra cada vez mais fundamental. No mesmo sentido, a busca incessante por alternativas e a própria abolição também. Os argumentos que constroem este texto têm esta audaciosa pretensão, ou seja, desconstruir lógicas de violência.

Desta maneira, conforme as palavras de Rodrigo Ghiringhelli de Azevedo (2000, pp. 100-101),

\begin{abstract}
no âmbito do sistema judicial, as reformas institucionais são apresentadas como tentativas de dar conta do aumento das taxas de criminalidade violenta, do crescimento geométrico da criminalidade organizada e do sentimento de insegurança que se verifica nos grandes aglomerados urbanos. A pressão da opinião pública, amplificada pelos meios de comunicação de massa, pressiona no sentido de uma maior eficácia, tendo como paradigma preferencial a chamada política de 'tolerância zero', adotada pela prefeitura de Nova lorque no início dos anos 90, e defendida por diferentes setores do espectro público. 0 pressuposto dessa política de segurança pública é a perda de eficácia das estratégias brandas ou informais de controle social.
\end{abstract}

É possível dizer, em consonância com o panorama apresentado acima por Azevedo (2000), que uma crise atravessa o direito penal e processual penal brasileiros:

Enquanto no direito penal percebe-se uma desenfreada busca da segurança [pública] através da edição de inúmeras leis penais, do aumento das penas em abstrato já existentes e da criação de novos tipos penais inseridos em leis atualmente em vigor, no processo penal é possível dizer que três opções são colocadas à disposição dos atores jurídicos: (a) utiliza-se aquilo que Choukr [2002] chamou de Processo Penal de Emergência; (b) inicia-se o respeito à Constituição da República e a todos os seus princípios processuais penais (...); ou (c) passa-se a 
pensar em novas formas de administração da justiça criminal (Achutti, 2009, pp. 55-56). ${ }^{3}$

Para Azevedo (2004, p. 40), a expansão do direito penal é uma das tendências mais evidentes nas sociedades contemporâneas, com a invasão de "campos da vida social anteriormente não regulados por sanções penais. O remédio penal é utilizado pelas instâncias de poder político como resposta para quase todos os tipos de conflitos e problemas sociais." O direito penal acaba sendo utilizado de forma contingencial como mecanismo público de gestão de condutas, e não mais como última alternativa para a proteção de bens jurídicos.

Em relação ao processo penal, é possível verificar um alargamento dos poderes instrutórios do juiz, permitindo ao magistrado criminal exercer papel que deveria ser exclusivo das partes. Tal possibilidade contraria os postulados de um processo penal equilibrado, e seria a característica central do que Fauzi Hassan Choukr (2002) chama de processo penal de emergência, tendo as leis no. 8.072/1990, 9.034/1995, 9.613/1998 e 9.807/1999 como exemplos concretos da sua adoção no país. Concorda-se, quanto a este ponto, com Aury Lopes Jr. (2004), quando refere que tal estratégia não passa de mero paliativo frente à criminalidade, uma vez que o processo penal não serve para combater o crime e o delinqüente, mas tão-somente para que ninguém seja penalizado sumariamente, sem direito a defesa, contraditório, etc.

Contudo, na contramão do fundamento destas reformas ampliadoras do poder punitivo - verificadas tanto na esfera penal quanto na esfera processual penal - o Brasil possui um número aproximado de 515.000 (quinhentos e quinze mil) presos, ${ }^{4}$ o que representa a mais alta população carcerária da sua história e a terceira maior do mundo, atrás apenas dos Estados Unidos e da China. ${ }^{5}$

\footnotetext{
${ }^{3}$ Conferir também Azevedo e Carvalho (2006).

4 Fonte: InfoPen - Ministério da Justiça. Dados referentes a dezembro de 2011. Disponível em http://portal.mj.gov.br/depen/data/Pages/MJD574E9CEITEMIDC37B2AE94C6840068B1624D28407509CPT BRNN.htm . Acesso em 10 de fevereiro de 2012.

${ }^{5}$ Fonte: Conselho Nacional de Justiça (CNJ). Disponível em http://www.cnj.jus.br/portal/noticias/9874brasil-tem-terceira-maior-populacao-carceraria-do-mundo. Acesso em 10 de abril de 2012.
} 
Considerando ainda que aproximadamente 670.000 (seiscentas e setenta mil) pessoas estão cumprindo penas ou medidas alternativas, ${ }^{6}$ o número total aproximado de pessoas atualmente em contato com o sistema legal de controle do crime alcança a vultosa cifra de 1.185 .000 (um milhão, cento e oitenta e cinco mil). Esta soma explicita o considerável equívoco do raciocínio que cobra o endurecimento das leis penais e um maior rigor na sua aplicação, e sugere que o poder punitivo brasileiro nunca foi tão efetivo quanto agora.

Entretanto, paralelamente ao aumento do poder punitivo do Estado mencionado acima, Azevedo (2001, p. 99) chama a atenção para o fato de que os estudos sociológicos e antropológicos sobre o sistema jurídico das últimas décadas do século XX tiveram influência na criação de novas estratégias de controle penal, paradoxalmente menos punitivas, onerosas e formais, "de modo a maximizar o acesso aos serviços, diminuir a morosidade judicial e equacionar os conflitos por meio da mediação". No âmbito penal, verificaram-se movimentos de descriminalização de condutas e de informalização, e no âmbito processual penal, uma mais ampla utilização do princípio da oportunidade da ação penal nos delitos de menor potencial ofensivo, e a incorporação da vítima nos estágios iniciais do processo.

Em termos concretos,

As alternativas de informalização apontam para a redução da competência do sistema penal tradicional em relação ao controle de condutas que permanecem sendo consideradas socialmente indesejáveis. São as chamadas soluções conciliatórias, que visam promover a interação face a face entre vítima e acusado como forma de superar o conflito que está na origem do delito. As soluções de conciliação constituem uma das manifestações mais expressivas do movimento de deslegalização ou informalização da justiça (Azevedo, 2001, p. 99).

Nesse contexto, a lei n. 9.099/95 (Lei dos Juizados Especiais Cíveis e Criminais) pode ser apontada como uma tentativa de fazer frente à crise do processo penal tradicional e, portanto, como um sintoma formal da referida crise, diante da incorporação

\footnotetext{
${ }^{6}$ Os dados disponíveis no sítio eletrônico do Ministério da Justiça se referem ao ano de 2009, e informam que 671.078 pessoas encontravam-se cumprindo penas ou medidas alternativas. Disponível em http://portal.mj.gov.br/main.asp?ViewID=\{47E6462C-55C9-457C-99EC5A46AFC02DA7 $\} \&$ params $=$ itemID $=\{38622 B 1 F-F D 61-4264-8 A D 4-02215 F 6598 F 2\} ; \& U I P a r t U I D=\{2868 B A 3 C-$ 1C72-4347-BE11-A26F70F4CB26\}. Acesso em 10 de fevereiro de 2012.
} 
de tais inovações no sistema judicial brasileiro, em especial nos trâmites processuais relativos aos delitos de menor potencial ofensivo (Azevedo, 2001, p. 100).

Ao buscar um paradigma diferenciado para o processamento judicial de tais delitos, o legislador teria optado por outro mecanismo, para buscar uma maior efetividade na resolução de conflitos e, consequentemente, reduzir a quantidade excessiva de trabalho verificada, à época, nas varas criminais comuns. O tempo de trabalho dispensado a processos envolvendo pequenos delitos impedia uma maior dedicação aos casos criminais realmente graves (Azevedo, 2000, p. 148).

Em um contexto em que propostas de política criminal que apontam ora para o endurecimento do sistema penal e ora para medidas informalizadoras, impõe-se um questionamento central: ainda que tais propostas legislativas sejam incorporadas ao sistema penal brasileiro, não seria mais adequado pensar, dado o elevado nível de violência do próprio sistema penal, em alternativas radicais ao modo de funcionamento da justiça criminal?

Pelo que facilmente se percebe, as medidas de endurecimento e de informalização não produzem o efeito esperado e colaboram incisivamente para a ampliação do controle social penal e, portanto, da violência. Não há inovação, mas mera manutenção de um sistema que, desde os primeiros momentos do iluminismo penal, mostra-se ineficaz e seletivo, e não se pode cogitar ter chegado perto daquilo que prometiam seus discursos legitimadores (reeducação, ressocialização, etc.).

Por este motivo, cumpre trazer à baila as críticas de Louk Hulsman, Nils Christie e Thomas Mathiesen à justiça criminal: ao apontar seus principais problemas e sinalizar para uma forma efetivamente alternativa de administrar os conflitos tutelados por esta instituição criminal, foram considerados como os principais responsáveis pelas proposições do movimento do abolicionismo penal.

Contudo, antes de defender o fim do sistema penal como um todo, é imperativo questionar: as críticas de Hulsman, Christie e Mathiesen, ao insinuarem a necessidade de um sistema efetivamente desvinculado da justiça criminal tradicional, com foco voltado para as necessidades das partes envolvidas no conflito, não estariam a indicar que, de 
fato, apenas com um novo mecanismo de gestão dos conflitos criminais seria possível avançar nesta seara?

É o que se pretende trabalhar neste breve trabalho, a partir da obra O Alienista, de Machado de Assis. Publicada ao longo dos anos 1881 e 1882, permite que hoje, em meio a um momento de plena expansão do direito penal, seja possível questionar a real efetividade do hiperencarceramento e, paralelamente a isto, se a opção pelo sistema penal é, de fato, uma opção desejável.

\section{A Violência Performativa do Direito.}

Vivemos atualmente a experiência daquilo que se chama populismo penal. Em outras palavras, trata-se de punitivismo mesmo. Vivemos a experiência do controle total, em que os desdobramentos da violência referida acima atingem níveis cada vez maiores. E isto não é sem razão: pulsa no âmago do direito uma pretensão totalizante de controle que se mostra, dia-a-dia, mais explícita. Com uma cartilha de boas intenções, poderíamos citar como exemplos os discursos de lei e ordem, defesa social e interesse público. 0 direito amplia sua dimensão de controle sobre o real, sobre a vida propriamente dita. Nada, absolutamente nada pode escapar desta máquina, no mais genuíno sentido Kafkiano (Kafka, 1998).

A ambivalência desta experiência do controle totalizante, com fundamento na promessa de segurança - um dos fundamentos da modernidade - é justamente o sofrimento oriundo da violência própria do direito. Como referimos acima, os números de encarceramento crescem de forma avassaladora. No mesmo sentido, de modo dissimulado o poder cria novos mecanismos ou dispositivos de controle. A promessa da informalização da justiça pode ter sido uma das tantas dissimulações do poder (punitivo) - e dá sinais de que continuará a controlar a população de forma cada vez mais abrangente, como comprova o mecanismo do monitoramento eletrônico, exemplo perfeito do controle além-muro.

A questão do controle está intimamente relacionada à questão da governabilidade. E, nesse sentido, é importante especificar o que pretendemos dizer quando falamos em dispositivos. Segundo Agamben (2009, p. 38), “o termo dispositivo nomeia aquilo em que e por meio do qual se realiza uma pura atividade de governo sem 
nenhum fundamento no ser". Assim, é por não ter nenhum fundamento no ser que torna possível uma atividade pura de governo, ou seja, torna-se possível o dispositivo propriamente dito.

Além disso, por não ter nenhum fundamento no ser, refere Agamben (2009, p. 38) que "os dispositivos devem sempre implicar um processo de subjetivação, isto é, devem produzir o seu sujeito". Em outras palavras, os dispositivos produzem os seus sujeitos. Assim, vivemos também esta experiência, qual seja, a de um modo de vida cuja governabilidade se impõe por dispositivos de controle e que produz uma subjetivação específica, justamente para este modo de ser.

Em termos mais específicos, para além dos dispositivos foucaultianos, Agamben (2009, pp. 40-41) refere:

Chamarei literalmente de dispositivo qualquer coisa que tenha de algum modo a capacidade de capturar, orientar, determinar, interceptar, modelar, controlar e assegurar os gestos, as condutas, as opiniões e os discursos dos seres viventes. Não somente, portanto, prisões, os manicômios, o Panóptico, as escolas, a confissão, as fábricas, as disciplinas, as medidas jurídicas etc., cuja conexão com o poder é num certo sentido evidente, mas também a caneta, a escritura, a literatura, a filosofia, a agricultura, o cigarro, a navegação, os computadores, os telefones celulares e - por que não - a própria linguagem, que talvez é o mais antigo dos dispositivos, em que há milhares de anos um primata - provavelmente sem se dar conta das consequências que se seguiriam - teve a inconsciência de se deixar capturar.

Os dispositivos, portanto, regulam o nosso modo de ser, ou seja, a nossa própria existência. O ápice desta proliferação de dispositivos talvez seja, segundo Agamben, o capitalismo. O controle, ou a forma de governo, exercido através dos dispositivos, não escapam à oikonomia, que é, para Agamben (2009, p. 39), "um conjunto de práxis, de saberes, de medidas, de instituições, cujo objetivo é gerir, governar, controlar e orientar, num sentido que se supõe útil, os gestos e o pensamento dos homens".

Acontece que, atualmente, estes mecanismos, esta máquina de governo, impõe uma outra produção de sujeitos, ou seja: passamos por um processo de dessubjetivação do sujeito (Agamben, 2009, p. 46). Por certo, a manipulação dos sujeitos faz parte do programa de governabilidade do real. E o direito (penal) não escapa a estas dimensões. Aliás, talvez seja um dos principais dispositivos de governabilidade. Além disso, os níveis 
de tecnicismo e burocracia estão tão elevados que podemos acreditar que também impõe a dessubjetivação dos sujeitos.

Mas tudo isso não é sem razão, como mencionado acima. Esta lógica imposta ao modo de vida atual é fruto de uma razão que, justamente, permite esta condição existencial por assim dizer. A esta razão, Theodor Adorno denomina instrumental.

Esta racionalidade, dentre outras coisas, possibilita um distanciamento entre a técnica e a moral. Este distanciamento acaba por causar uma crise de sentido, seja na perspectiva singular, seja na perspectiva institucional. Dito de outro modo, acaba por ensejar o enrijecimento das relações sociais. Além disso, faz com que, de alguma forma, paremos de nos perguntar: por quê fazemos o que fazemos?

Em matéria penal isto se torna cada vez mais evidente, na medida em que sequer conseguimos estabelecer reflexões acerca de outras possibilidades no que diz respeito à violência criada e resignificada diariamente pelo sistema penal. A opção pelo encarceramento está tão fortemente marcada em termos de cultura de controle do crime, que a mera especulação de uma alternativa já representa uma ousadia desmedida para o senso comum. Daí porque as propostas que partem das críticas oriundas do abolicionismo penal serem tão estigmatizadas.

A questão propriamente dita sobre o questionamento das práticas punitivas, dos dispositivos de controle, ou o por quê fazemos o que fazemos?, é que entrelaça os argumentos deste texto: busca-se compreender porque naturalizamos a técnica no quotidiano, mesmo sabendo dos efeitos perversos da sua aplicabilidade.

\section{A Crítica Machadiana ao Cientificismo: da vontade de controle do mundo ao} reconhecimento da limitação humana.

A par disso, encontramos na literatura, precisamente na obra $O$ Alienista, de Machado de Assis, uma ótima chave de leitura daquilo que experimentamos em termos de controle, vigilância, encarceramento e violência do sistema penal. Por óbvio, não há a pretensão de esgotar a multiplicidade de sentidos desta obra clássica da literatura brasileira, mas apenas refletir sobre questões importantes que, na nossa leitura, fazem todo o sentido com o objetivo deste texto. 
Trata-se de crônicas da Vila de Itaguaí, em que dizem que em tempos remotos vivera ali um médico, chamado Dr. Simão Bacamarte. Narram ainda que o médico é filho da nobreza da terra e o maior dos médicos do Brasil, de Portugal e das Espanhas. Estudou em Coimbra e Pádua, e com 34 anos regressou ao Brasil, optando por não ficar em Coimbra regendo a Universidade, ou em Lisboa regendo os negócios da monarquia. Em diálogo com o el-rei, Dr. Bacamarte disse o seguinte: "A ciência, é o meu emprego único; Itaguaí é o meu Universo" (Assis, 2006, p. 13).

A Vila de Itaguaí se tornará então o universo do médico, cuja ciência é seu único e exclusivo emprego. Contam as crônicas de Itaguaí que, após chegar a Vila, o Dr. Bacamarte dedicou-se de corpo e alma ao estudo das ciências, alternando curas, leituras, bem como com a demonstração de teoremas em cataplasmas (Assis, 2006, p. 13). Nada mais consta nas crônicas em relação ao período entre a sua chegada e seu casamento, quando estava já com 40 anos. O que nos permite acreditar que tenha realmente se dedicado exclusivamente à ciência médica, ou, como respondeu a Sua Majestade, de corpo e alma. Casou-se com D. Evarista da Costa e Mascarenhas, então com 25 anos e viúva de um juiz de fora. Dentre suas qualidades, não estavam a beleza e a simpatia.

Em resposta a um dos tios desta jovem senhora, Simão Bacamarte explicou o seguinte: "que D. Evarista reunia condições fisiológicas e anatômicas de primeira ordem, digeria com facilidade, dormia regularmente, tinha bom pulso e excelente vista; estava apta assim para the dar filhos robustos, sãos e inteligentes". A escolha do médico, portanto, se justificava pelas excelentes aptidões fisiológicas e anatômicas. Em tese, o grande médico poderia esperar que seus filhos nascessem com as melhores das heranças genéticas. O fato de a jovem senhora não possuir feições privilegiadas não preocupava o médico - antes pelo contrário, afinal, um sábio não deveria ter preocupações desta ordem. Além disso, tendo como interesse principal a ciência, este seria mais um motivo para agradecer pelas feições de sua esposa.

Ocorre que D. Evarista não correspondeu às expectativas de Bacamarte. A jovem senhora não the deu filhos. Após esperar cinco anos, contam as crônicas, o Dr. Bacamarte fez um estudo profundo sobre o tema, releu todos os escritores árabes e outros, que trouxera a Itaguaí, consultou Universidades italianas e alemãs, e aconselhou à mulher um 
regime alimentar especial. Todavia, mesmo com o regime especial, não houve resultado, razão pela qual foi extinta a dinastia dos Bacamarte (Assis, 2006, p. 14).

Assim, com a mágoa de não ter filhos, o médico dedicou-se inteiramente ao estudo da medicina. Foi neste período que uma área em especial lhe chamou a atenção: $o$ exame da patologia cerebral. Não havia na colônia e nem no Reino uma só autoridade nesta área médica. A matéria era muito mal explorada. As crônicas referem que o médico compreendeu que a ciência lusitana, e particularmente a brasileira, poderia cobrir-se de "louros imarcescíveis", embora exteriormente o Dr. fosse modesto. Para o Dr. Bacamarte, a saúde da alma era a ocupação mais digna do médico (Assis, 2006, p. 14).

Até então, na Vila de Itaguaí se fazia pouco caso dos dementes. Deste modo, as crônicas referem que cada louco furioso era trancado em uma alcova, na própria casa, até a sua morte. Não havia cura. Em contrapartida, os loucos ditos mansos andavam À solta pelas ruas. Assim, Bacamarte decidiu pedir autorização à Câmara para agasalhar e tratar e tratar, no edifício que iria construir, todos os loucos de Itaguaí e das demais vilas e cidades. A intenção do médico era reformar o mau costume de não curar os loucas da colônia. A proposta despertou curiosidade e resistência. A ideia de colocar todos numa casa pareceu, para alguns, sintoma de demência, e algumas insinuações foram feitas, inclusive em relação à esposa do médico (Assis, 2006, p. 15).

Apesar das resistências e das insinuações, o médico se valeu da sua astucia para conseguir a autorização e a licença da Câmara. Assim, de pronto começou a construção da casa, que fora nomeada Casa Verde. A inauguração durou sete dias, com imensa pompa, e já com alguns dementes recolhidos a casa. Após os festejos, com a casa devidamente inaugurada, Bacamarte disse o seguinte:

O principal nesta minha obra da Casa Verde é estudar profundamente a loucura, os diversos graus, classificar-lhe os casos, descobrir enfim a causa do fenômeno e o remédio universal. Este é o mistério do meu coração. Creio que com isto presto um bom serviço à humanidade (Assis, 2006, pp. 17-18).

Em quase quatro meses, contam as crônicas, a Casa Verde já estava lotada. Os loucos vinham de todos os lugares, inclusive das cidades vizinhas. Tal fato impressionou o Padre de Itaguaí, que não acreditava na existência de tantos doidos no mundo. 
Para cada questionamento em relação a real demência de alguma pessoa, o alienista sempre rebatia com uma resposta científica, afinal era a única autoridade na área. Deste modo, tendo em vista que pretendia prestar um grande serviço à humanidade com seus estudos científicos sobre a loucura, o médico dividiu os enfermos em duas grandes classes: os furiosos e os mansos. Após esta classificação, fez diversas subclasses e iniciou um estudo minucioso sobre cada louco. Bacamarte, neste período, dormia mal e comia pouco, dedicando-se de corpo e alma à sua atividade científica.

O alienista pretendia construir uma nova teoria, que iria alargar as bases da psicologia. Tratava a ciência como experiência. Para ele, a ciência era uma investigação constante, o que o impedia de afirmar suas ideias de início. Para Bacamarte "a loucura, objeto dos meus estudos, era até agora uma ilha perdida no oceano da razão; começo a suspeitar que é um continente". Para o alienista era possível demarcar os limites da razão. Segundo ele "a razão é o perfeito equilíbrio entre de todas as faculdades; fora daí insânia, insânia, e só insânia" (Assis, 2006, pp. 26 e 28).

O número de pessoas recolhidas só aumentava na Casa Verde, gente que nunca ninguém suspeitou acabou recolhida, e isto começou a aterrorizar a Vila de Itaguaí. Muitos desacreditavam das justificativas científicas do alienista. Apesar de toda desconfiança, o médico seguia sua tarefa científica - não se restringindo à Casa Verde, mas também andando pela cidade observando as pessoas e recolhendo-as caso entendesse perceptível alguma demência.

A situação chegou ao limite e uma rebelião se instaurou na Vila. Houve representação junto à Câmara para cassar a licença da Casa Verde. A casa foi denominada pelos rebeldes como "a Bastilha da razão humana" (Assis, 2006, p. 43). Em uma sessão na Câmara, após ouvir esta expressão, um vereador que apoiava o presidente questionou: "nada tenho que ver com a ciência; mas se tantos homens em quem supomos juízo são reclusos por dementes, quem nos afirma que o alienado não é o alienista?" (Assis, 2006, p. 44).

A rebelião gerou um conflito, que resultou em onze mortes e vinte e cinco feridos. Muitos acontecimentos políticos são narrados pelas crônicas, inclusive a troca de governo na Vila. A crise não abalou a atividade científica do alienista. Bacamarte seguiu 
recolhendo gente à Casa Verde. Apoiadores do novo governo, o secretário: praticamente ninguém escapava. A loucura era total. Desde a mais simples mentira, ninguém escapava dos emissários do alienista (Assis, 2006, p. 60). Bacamarte recolheu a própria esposa à Casa Verde.

Diante do grande número de pessoas recolhidas a Casa Verde (quatro quintos da população estava recolhido neste estabelecimento), o alienista resolveu soltar todos, oficiando a Câmara sobre as suas conclusões científicas. Tal fato assombrou a Vila. Mas, de fato, foi o que aconteceu. Segundo o alienista, as estatísticas de pessoas recolhidas o fizeram examinar os fundamentos da sua teoria das moléstias cerebrais - teoria esta que excluía do domínio da razão todos os casos em que o equilíbrio das faculdades não fosse perfeito e absoluto. Além disso, deste exame resultou para ele a convicção de que $a$ verdadeira doutrina não era aquela, mas a oposta, ou seja, as hipóteses patológicas seriam todas aquelas em que o equilibrio fosse ininterrupto (Assis, 2006, p. 63).

Todas as pessoas que estavam na Casa Verde foram, portanto, colocadas em liberdade. Um novo paradigma foi descoberto pelo alienista. Agora, as patologias se configurariam quando se verificasse equilíbrio ininterrupto das faculdades mentais do sujeito. O normal passou a ser o desequilíbrio, segundo a revisão dos fundamentos teóricos do Dr. Bacamarte. Desde a nova concepção teórica do alienista, foi-lhe permitido seguir com seu trabalho científico. Em cinco meses e meio, com o mais racional sistema terapêutico, a Casa Verde Estava Vazia, estavam todos curados.

Mas o alienista não ficou radiante ao ver seu último hóspede sair. Não lhe bastou ter descoberto a verdadeira teoria da loucura, não o contentou ter estabelecido em Itaguaí o reino da razão (Assis, 2006, p. 73). Algo Ihe dizia que a nova teoria tinha em si uma novíssima hipótese. E pensando sobre o que havia acontecido, o alienista tentava chegar, enfim, à última verdade.

Assim, o alienista concluiu que não haviam loucos em Itaguaí, mas que havia apenas um mentecapto: ele mesmo (Assis, 2006, p. 74). Desse modo, resolveu se recolher na Casa Verde - afinal, a questão era científica. Entregou-se à própria cura e, contam as crônicas, morreu dali a dezessete meses. 
Veja-se que o excesso de controle exercido pelo Dr. Bacamarte e a sua conclusão final apresentam semelhança interessante com o sistema penal brasileiro: enquanto muito se tenta fazer para efetivar "mais do mesmo" - com novos mecanismos de controle social por meio do direito penal (intra ou extra muros), com a construção interminável de presídios para suprir a carência de vagas no sistema prisional, ou com a "contratação" de mais e mais atores jurídicos (juízes, promotores, defensores públicos, funcionários de cartórios, etc.) - em poucos momentos (ou, talvez, em nenhum momento) se percebe qualquer discussão ou debate sobre a real necessidade de manutenção de um sistema que, desde que iniciou a operar, jamais conseguiu chegar perto de seus objetivos. A não ser que seu objetivo tenha sido, desde o início, manter um patamar insuperável de desigualdade e de violência, o que permitiria concluir que, neste caso, o sucesso do sistema seria incontestável.

Na contramão de propostas de manutenção do sistema penal tal como ele existe e opera contemporaneamente, e buscando sempre um questionamento sobre os dispositivos de controle social, percebe-se nas estigmatizadas críticas e propostas abolicionistas uma válvula de escape (talvez uma das poucas possíveis). Ao questionar o nervo exposto ${ }^{7}$ do sistema penal, os abolicionistas permitem que se pense sobre os motivos que levaram não apenas ao hiperencarceramento contemporâneo, mas fundamentalmente a um uso desmesurado dos mecanismos de controle penal.

Para além da razão técnico-burocrática, como se demonstrará, o abolicionismo penal não apenas estabelece a crítica mais contundente ao sistema penal, mas permite também entrever possibilidades concretas de rompimento com a lógica perversa da governabilidade por meio de instrumentos enjauladores. Afinal, a manutenção e o incremento da máquina penal não nos colocam diante do mesmo questionamento do personagem de Machado de Assis.

\section{O Abolicionismo Penal: crítica e extinção do sistema penal.}

O abolicionismo penal - corrente teórica cuja própria denominação indica as suas pretensões - tem seu foco voltado para a construção de uma crítica capaz de deslegitimar de forma radical o sistema carcerário e a sua lógica punitiva (Anitua, 2008, p. 697).

\footnotetext{
${ }^{7}$ A referência, aqui, é explícita ao artigo de Souza (2010). 
Serão utilizados três trabalhos de autores fundamentais do abolicionismo, que delineiam as críticas do sistema formal de justiça criminal e expõem as principais pretensões do movimento: "As Políticas da Abolição" (The Politics of Abolition - 1974), de Thomas Mathiesen; "Conflitos como Propriedade" (Conflicts as Property - 1977), de Nils Christie; e "Criminologia Crítica e o Conceito de Delito" (Critical Criminology and the Concept of Crime - 1986), de Louk Hulsman. Vários outros artigos e livros poderiam ser citados, mas estes três são suficientes para as pretensões do presente trabalho.

\subsection{Ideias gerais - Hulsman, Mathiesen e Christie.}

De forma resumida, o abolicionismo defende a ideia de que o castigo não é o meio mais adequado para reagir diante de um delito, e por melhor que possam ser, eventuais reformas no sistema criminal não surtirão efeito, pois o próprio sistema está equivocado ao estabelecer que com uma resposta punitiva (pena de prisão) o "problema" do delito estará solucionado.

No âmago da sua argumentação, o abolicionismo - através principalmente de Hulsman - propõe-se a desconstruir a definição de delito: o delito não seria o objeto, mas o produto de uma política criminal que pretende justificar o exercício do poder punitivo, e não possuiria realidade ontológica. De acordo com o autor, a partir de então seria possível reorganizar o debate da criminologia e da política criminal, e tal postura apontaria para a abolição da justiça penal, uma vez que "o delito como realidade ontológica" seria a pedra fundamental deste tipo de justiça (Hulsman, 1986, p. 67).

Pelas palavras de Anitua (2008, p. 698),

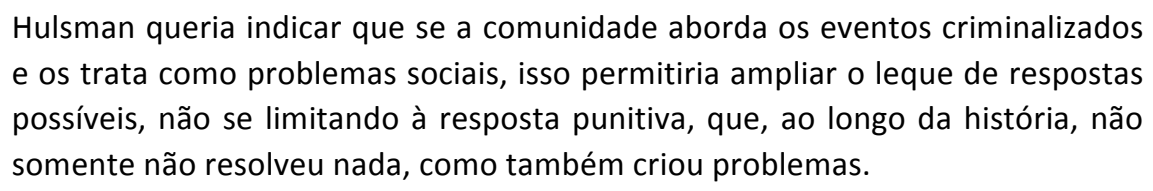

Uma das maneiras para concretizar a desconstrução da categoria delito e viabilizar a adoção de outros mecanismos de controle social seria a adoção de um novo vocabulário para abordar a questão criminal e as engrenagens oficiais: a linguagem delimita o sistema e mascara a realidade, de forma a (a) excluir qualquer tentativa de utilização de mecanismos diversos aos oficialmente existentes; e (b) de definir os conflitos não a partir 
do ponto de vista dos envolvidos, mas a partir da prévia estruturação legal desses conflitos, tidos oficialmente como delitos.

Tais definições, uma vez que realizadas anteriormente à ocorrência do conflito, não permitem a construção coletiva acerca da situação e de suas circunstâncias: a única leitura possível é a leitura jurídico-penal. Em um contexto de organização formal em que a própria definição preliminar do caso (geralmente, realizada pela polícia e pelo Ministério Público) não está à disposição das partes, as conseqüências do julgamento, naturalmente, também não serão colocadas em discussão (Hulsman, 1986, p. 77-78).

Para Hulsman (1986, p. 77), a estruturação legal de conflitos como delitos pouco ou nada poderia coincidir com a visão do problema que teriam as partes diretamente envolvidas: "Na justiça penal geralmente se decide de acordo com uma realidade que existe apenas dentro do sistema, e raramente encontra a sua contrapartida no mundo exterior".

Conseqüentemente, Hulsman propõe uma mudança significativa de linguagem, uma vez que o crime não possui existência ontológica e, portanto, não necessariamente deve ser chamado dessa forma. A proposta do autor remonta à expressão "situações problemáticas", e a pretensão era reduzir ou anular a estigmatização oriunda do sistema penal e devolver a resolução do conflito às partes (Hulsman e Celis, 1997, p. 101 e 96). Tal mudança teria o poder de romper o binômio crime-castigo e oferecer uma gama infindável de possibilidades para encerrar e resolver a situação sem precisar recorrer à tradicional pena de prisão.

Suas críticas ao sistema penal, como se sabe, não estavam isoladas: Thomas Mathiesen, no seu livro As Políticas da Abolição, apresentava três propostas principais para a efetivação do abolicionismo penal. Em primeiro lugar, a abolição das prisões era considerada como um objetivo de uma política criminal radical. Tal proposta foi reafirmada em 1986, em artigo de mesmo nome no qual o autor revisou o trabalho original e, constatando a expansão considerável do uso da prisão no mundo ocidental, reiterou que o objetivo apresentado vinte e dois anos antes se encontrava revigorado: quanto mais as pessoas são colocadas atrás das grades, mais importante ainda se tornou o mencionado objetivo (Mathiesen, 1986, p. 84). 
Em segundo lugar, era necessário ter cuidado com as conhecidas "alternativas" à prisão, uma vez que isso poderia facilmente implicar na criação de estruturas prisionais semelhantes, com funções igualmente muito parecidas (Mathiesen, 1986, p. 81). Diante de tal situação, Mathiesen propôs a sua conhecida "política do inacabado" (unfinished policies), que preza pela constante atenção dos abolicionistas para jamais deixar de lutar pela abolição da prisão ou, pelo menos, para questionar todas as formas de alternativas que pudessem ser propostas oficialmente à prisão. Dessa forma, a "luta abolicionista" não tem fim aparente, e é necessário estar sempre pronto para confrontar toda proposta possível de ampliação da malha prisional.

Por fim, propunha o autor que, para a realização do objetivo principal, era necessária "uma estratégia muito bem trabalhada, e acima de tudo uma análise da relação entre as reformas de curto prazo e a abolição a longo prazo." Em relação às reformas de curto prazo, o adequado seria adotar uma postura "negativa", no sentido de sempre se posicionar contrariamente a qualquer proposta que pudesse incrementar ou aumentar o sistema prisional (Mathiesen, 1986, p. 82).

Nils Christie, por sua vez, no clássico Conflitos como Propriedade, igualmente faz uma severa crítica ao sistema penal, mas estabelece o centro da discussão na apropriação estatal dos conflitos. Diante da constatação de que aqueles que lidam com os conflitos são pessoas alheias às partes (juízes, promotores e advogados), Christie opõe ao modelo tradicional de justiça criminal uma outra forma de trabalhar os conflitos, de estrutura descentralizada e cujos atores principais não seriam terceiras pessoas - ou profissionais da administração de conflitos - mas as próprias partes (direta ou indiretamente) envolvidas no conflito. Elas mesmas deveriam, de forma a buscar reparar o dano causado à vítima, buscar as soluções possíveis para os conflitos em que estiverem envolvidas.

Segundo o autor, os conflitos foram furtados das partes e entregues ao Estado, para que este pudesse determinar a responsabilidade e a punição ao ofensor. Os conflitos deveriam, segundo Christie, ser vistos como valiosos, que não poderiam ser desperdiçados e mal utilizados, uma vez que o potencial maior dos conflitos reside justamente em oportunizar aos cidadãos a administração de seus próprios problemas. Conseqüentemente, é fácil notar que os cidadãos adquirem uma maior autonomia em 
relação ao poder estatal, e a forma profissional de lidar com os conflitos abre espaço para um enfrentamento não massivo e particular da situação.

A importância do artigo de Christie, para além da contundente crítica que estabelece ao sistema de justiça criminal, remonta de forma especial ao retorno da vítima na participação da resolução de seu caso. Conforme o autor (Christie, 1977, p. 8), as vítimas precisam compreender a situação, mas a justiça criminal as trata como "uma nãopessoa em uma peça de Kafka".

A seguir, o autor coloca que o modelo de justiça em questão deve possuir como foco não o ofensor, mas a vítima e as necessidades que surgiram com o conflito. Além disso, o sistema idealizado por Christie seria constituído por tribunais comunitários (neighbourhood courts), de forma a estarem mais próximos aos valores da comunidade em que estiverem inseridos. O procedimento se constituiria em quatro etapas consecutivas: na primeira, seria averiguada a plausibilidade da acusação, a fim de evitar que terceiras pessoas possam ser responsabilizadas pelos atos de outros e que os direitos do acusado sejam violados; a segunda envolveria a elaboração de um relatório completo das necessidades da vítima, a ser formulado por ela própria, considerando o dano que the foi causado e as formas como ele pode ser restaurado ou minimizado; na terceira, seria realizada uma análise pelos tribunais comunitários acerca de uma possível punição ao ofensor, independentemente do que ocorrera a etapa anterior; por fim, uma discussão sobre a situação pessoal e social do ofensor seria realizada pelos mesmos participantes das etapas anteriores, com a finalidade de averiguar as suas eventuais necessidades. Através destas etapas, estes tribunais locais "representariam uma mistura de elementos de tribunais civis e penais, mas com uma forte ênfase nos aspectos civis" (Christie, 1977, p. 11).

Os argumentos dos três mais conhecidos autores do abolicionismo penal fornecem forte material crítico para avançar a discussão sobre o papel da justiça criminal contemporânea, assim como para questionar aquilo que, há pouco tempo atrás, parecia inquestionável: o direito e o processo penal fornecem ferramentas realmente suficientes para a administração dos conflitos criminais? O afastamento das partes é algo realmente desejado ou confunde-se com a necessidade de legitimação do sistema penal? 


\section{Por uma Nova Forma de Fazer Justiça: ou, para evitar uma enorme Casa}

Verde.

A redução da complexidade da cultura contemporânea ${ }^{8}$ a meras leis matemáticas ou jurídicas, tanto faz: a lógica é a mesma - acaba por apresentar uma simplificação insustentável: quando se trata de enfrentar uma ciência social aplicada como o Direito, cujos fenômenos não podem ser descritos através de fórmulas, corre-se o sério risco de um reducionismo muito próximo à irracionalidade. ${ }^{9}$

Pensar o direito penal como meio para efetivar uma resposta estatal em relação a um evento criminoso não só vai de encontro a toda e qualquer constatação de que o sistema penal não consegue efetivar as suas promessas, ${ }^{10}$ como também evidencia 0 conservadorismo característico da dogmática atinente ao tema. A insistente natureza redentora do direito penal submete os acusados em geral a uma situação injustificável, sustentada apenas pela crença de que a pena poderá "salvar" o criminoso e curá-lo, colaborando, portanto, para a "sociedade de bem".

Preconiza, ainda, que, por meio da pena, conseguirá fazer com que o sujeito possa se re: ressocializar, reeducar, reintegrar... ${ }^{11}$ Ou seja: é a lógica da resposta única para os mais diversos (e complexos) problemas e conflitos. ${ }^{12}$ Independente da variedade dos fatores envolvendo cada crime, a resposta é sempre igual: pena privativa de liberdade. Trata-se, em termos radicais, da anulação da diferença em termos concretos. De fato, o sistema opera com absoluta indiferença.

O que seria o direito penal, afinal, senão uma fórmula redutora de complexidade, ou então aquilo que Salo de Carvalho (2005, p. 311) chama de método de despedaçamento?

\footnotetext{
${ }^{8}$ Conferir: Souza (2008).

9 “(...) a simplicidade das leis constitui uma simplificação arbitrária da realidade que nos confina a um horizonte mínimo para além do qual outros conhecimentos da natureza, provavelmente mais ricos e com mais interesse humano, ficam por conhecer" (Santos, 2002, p. 72).

${ }^{10}$ Os trabalhos a seguir são suficientes para se chegar a tal conclusão: Bitencourt (1993); Hulsman e Celis (1997); e Zaffaroni (1999).

${ }^{11}$ Sobre os discursus 're', conferir: Zaffaroni (2001).

12 "A dita civilização do progresso material, fundada na ciência e na técnica, não pôde realizar, pois, a suposta felicidade ampla, geral e irrestrita, conforme prometera em suas origens históricas." (BIRMAN, 2007, p. 38)
} 
Em um primeiro momento, a argumentação abolicionista, apesar da sua intensa força crítica, parece fadada a desaparecer naturalmente, dado o idealismo de suas principais proposições. Entretanto, a relativização do conceito de delito (Hulsman), as posturas negativas em termos de política criminal (Mathiesen) e a defesa de uma justiça mais participativa e descentralizada (Christie) permitem entrever a possibilidade de uma política criminal concreta, realista, cuja estrutura encontra respaldo no modelo conhecido como justiça restaurativa. ${ }^{13}$

Como refere Ruggiero (2010, p. 1), “certamente há na postura abolicionista na proposição de que a administração da justiça penal por um Estado centralizado deve ser substituída por formas descentralizadas de regulação autônoma de delitos".

Ao passo que a crítica ao posicionamento abolicionista opta estrategicamente por, de antemão, considerá-la "idealista demais", é possível pensar justamente o contrário: que o abolicionismo, ao invés de ser apenas um punhado de críticas ao sistema penal com uma proposição utópica sobre o seu destino (abolição), é uma postura política, "uma forma de abordagem, uma perspectiva, uma metodologia e, acima de tudo, uma forma de enxergar" a evidente incompatibilidade entre a teoria e a prática do sistema de justiça criminal (Ruggiero, 2010, p. 1).

Mas essa não é uma questão apenas de "recolocar os textos abolicionistas de volta às estantes de referência das bibliotecas universitárias", mas de "vincular o 'radicalismo e o utopismo' abolicionistas com visões do crime e da lei incorporadas na tradição cultural ocidental e suas opções concretas e razoáveis que se destinam a redução de dor" (Ruggiero, 2010, p. 201).

Com tal perspectiva, de que é necessário repensar o panorama político-criminal brasileiro de forma completamente renovada, sem vínculos com o sistema e com a linguagem do direito penal, a justiça restaurativa abre espaço para um novo modo de fazer justiça e coloca no centro da discussão exatamente àquilo que é relegado a segundo plano pela política do hiperencarceramento: afinal, o que pensam as partes sobre o

\footnotetext{
${ }^{13}$ Para detalhes sobre a justiça restaurativa, conferir: Sica (2007) e Pallamolla (2009). 
conflito em que se envolveram? Será que não podem, elas mesmas, com o apoio de mediadores, propor uma solução mais inteligente ${ }^{14}$ para o seu problema?

Concluindo com Souza (2008), preferimos dizer que se trata da superação daquilo que há de mais arraigado em nós mesmos - quiçá, daquilo que nos incomoda até mesmo inconscientemente: o medo e o preconceito.

O preconceito, fruto do medo,

\begin{abstract}
em todas as suas formas é um sintoma explícito de uma patologia profunda e implícita no horizonte e em todas as dimensões da realidade considerada. Esta patologia profunda e degenerativa é a totalização da realidade em torno de um pólo único de sentido e de segurança, a radical solidão da razão, des-realidade, o monadismo levado às suas últimas conseqüências. (Souza, 2008, p. 36)
\end{abstract}

Que medo e que preconceito são esses, afinal, que nos impedem de assumirmos o novo? Onde está a vida, diante da cega estupidez da mediocridade? "O medo é o momento brutalizado, petrificado, mesmificado. É a mais sutil defesa contra a novidade verdadeira" (Souza, 2008, p. 37).

Ainda, o preconceito "só existe em egos fragilizados e que flutuam no limbo de sua própria indigência, navegando massivamente, irremediavelmente solitários - ou seja, sem a percepção da dimensão do solidário e a diversidade dos muitos mundos humanos no mar imenso do desconhecido." É "o óbvio, o direto, aquilo que não necessita de esforço para ser compreendido, para ser vivido; nega toda a racionalidade para poder fingir ter uma: o preconceito, de qualquer gênero ou amplitude, é a antifilosofia por excelência" (Souza, 2008, pp. 37 e 39, respectivamente).

Os preconceituosos "refugiam-se no sonho de um mundo puro, causa de sua causa, onde pudessem ser medíocres em paz, sem a ameaça do diferente e as cobranças, para eles insuportáveis, da racionalidade". (...) E o preconceito "nada mais é do que o medo; mas o medo por excelência neurótico, impossível, eterno, conceitual, cujo sofrimento não se auto-explicita - a miséria" (Souza, 2008, pp. 41 e 43, respectivamente).

E é, necessariamente, "apenas no tempo (...) [que] se pode dar a irrupção do novo. E o novo é a contra-posição - convite ao diálogo - do antigo (...); vida é mudança. (...) é percorrer a infinitude dos instantes sempre novos." (Souza, 2008, p. 43)

\footnotetext{
${ }^{14}$ Conferir: Garapon (2001). 
Tais considerações nos permitem concluir que toda ordem de intervenção jurídico-penal, conforme o modelo tradicional universalista de justiça criminal, hoje, está fadada a continuar como um retumbante fracasso, uma vez que pressupõe o êxito de uma razão já extensa e profundamente criticada: aquela, instrumental, ${ }^{15}$ que sustenta e legitima o sistema penal. Para além dessas questões, a falha é sempre a mesma: acreditar que é possível, através de sistemas universais, enfrentar situações específicas e singulares. Como diria Paul Feyerabend (2007, p. 16), "não há soluções gerais".

A conclusão, portanto, não poderia ser diferente: para superar o medo, o preconceito, o sistema penal e sua resposta única (pena), há que se criar espaços para o diálogo, onde a construção das respostas seja viabilizada e cada caso possa apresentar a resposta mais adequada, tal como propõe a justiça restaurativa, os mecanismos de mediação, dentre outras possibilidades. Não acreditamos que esse modelo de justiça criminal vá "solucionar os males do mundo", mas, quiçá, poderá evitar que passemos a viver em uma Casa Verde de dimensões continentais.

\section{REFERÊNCIAS BIBLIOGRÁFICAS}

ACHUTTI, Daniel. Modelos Contemporâneos de Justiça Criminal. Porto Alegre: Livraria do Advogado, 2009.

ADORNO, Theodor; HORKHEIMER, Max. Dialética do Esclarecimento. Rio de Janeiro: Jorge Zahar, 1985.

AGAMBEN, Giorgio. O que é um dispositivo? In: O que é contemporâneo e outros ensaios. Trad. Vinícius Nicastro Honesko. Chapecó: Argos, 2009.

ANITUA, Gabriel Ignacio. Histórias dos Pensamentos Criminológicos. Rio de Janeiro: Revan, 2008.

ASSIS, Machado de. O alienista. Porto Alegre: L\&PM, 2006.

\footnotetext{
${ }^{15}$ Conferir: Adorno e Horkheimer (1985). 
AZEVEDO, Rodrigo Ghiringhelli. Informalização da Justiça e Controle Social: estudo sociológico da implantação dos juizados especiais criminais em Porto Alegre. São Paulo: IBCCRIM, 2000.

Juizados Especiais Criminais. Uma abordagem sociológica sobre a informalização da justiça penal no Brasil. In: Revista Brasileira de Ciências Sociais, vol.16, n. 47, 2001.

- Tendências do Controle Penal na Época Contemporânea: reformas penais no Brasil e na Argentina. In: São Paulo em Perspectiva, vol. 18, n. 1, 2004.

BIRMAN, Joel. A Sustentável Leveza do Psicanalista: variações sobre o desamparo e a feminilidade. In: Mal-Estar na Atualidade: a psicanálise $e$ as novas formas de subjetivação. Rio de Janeiro: Civilização Brasileira, 2007.

BITENCOURT, Cezar Roberto. Falência da Pena de Prisão: causas e alternativas. São Paulo: Revista dos Tribunais, 1993.

CARVALHO, Salo de. Criminologia e Transdisciplinaridade. In: Revista do Instituto Brasileiro de Ciências Criminais, n. 56, São Paulo: Revista dos Tribunais, 2005.

CHOUKR, Fauzi Hassan. Processo Penal de Emergência. Rio de Janeiro: Lumen Juris, 2002.

CHRISTIE, Nils. Conflicts as Property. In: The British Journal of Criminology, vol. 17, n. 1, 1977.

FEYERABEND, Paul. Contra o Método. São Paulo: UNESP, 2007.

GARAPON, Antoine; GROS, Frédéric; PECH, Thierry. Punir em Democracia. E a justiça será. Lisboa: Piaget, 2001.

HULSMAN, Louk. Critical Criminology and the Concepto of Crime. In: Contemporary Crises (atualmente, Crime, Law and Social Change), vol. 10, n. 1. Amsterdam: Elsevier, 1986.

; CELIS, Jacqueline Bernat de. Penas Perdidas: o sistema penal em questão. 2. ed. Niterói: Luam, 1997.

KAFKA, Franz. O veredicto e Na colônia penal. São Paulo: Companhia das Letras, 1998.

LOPES JUNIOR, Aury. Introdução Crítica ao Processo Penal (Fundamentos da Instrumentalidade Garantista). Rio de Janeiro: Lumen Juris, 2004.

MATHIESEN, Thomas. The Politics of Abolition. In: Contemporary Crises (atualmente, Crime, Law and Social Change), vol. 10, n. 1. Amsterdam: Elsevier, 1986.

PALLAMOLLA, Raffaella da Porciuncula. Justiça Restaurativa: da teoria à prática. São Paulo: IBCCRIM, 2009. 
RUGGIERO, Vincenzo. Penal Abolitionism: a celebration. Oxford: Oxford University Press, 2010.

SANTOS, Boaventura de Sousa. A Crítica da Razão Indolente: contra o desperdício da experiência. São Paulo: Cortez, 2002.

SICA, Leonardo. Justiça Restaurativa e Mediação Penal: o novo modelo de justiça criminal e de gestão do crime. Rio de Janeiro: Lumen Juris, 2007.

SOUZA, Ricardo Timm de. Em Torno à Diferença: aventuras da alteridade na complexidade da cultura contemporânea. Rio de Janeiro: Lumen Juris, 2008.

O Nervo Exposto: Por uma crítica da ideia de razão desde a racionalidade ética. In: Criminologia e Sistemas Jurídico-Penais Contemporâneos II. Porto Alegre: Edipucrs, 2010.

ZAFFARONI, Eugênio Raúl. Desafios do Direito Penal na Era da Globalização. In: Revista Consulex, ano V, n. 106. Brasília: Consulex, 2001.

ZAFFARONI, Eugênio Raúl. Em Busca das Penas Perdidas: a perda de legitimidade do sistema penal. 4. ed. Rio de Janeiro: Revan, 1999. 